\title{
An Optimization Model for Scheduling Tour of Service Personnel in after- Sale Service Process with Additional Side Conditions of Responsiveness and FCFS Service Policy
}

\author{
Devendra Choudhary ${ }^{1 *}$, Bhamu JP2 and Jakhar OP ${ }^{2}$ \\ ${ }^{1}$ Department of Mechanical Engineering, Government Engineering College Ajmer, Rajasthan, India \\ ${ }^{2}$ Department of Mechanical Engineering, Government Engineering College Bikaner, Rajasthan, India
}

\begin{abstract}
In this paper a binary integer linear programming model is proposed for scheduling tour of service personnel in aftersale service process. The model aims to minimize the service personnel's overall travel time of visiting all customers with additional side conditions that customers should be served by first come first serve (FCFS) priority basis within specified service response time. These side conditions are important strategies in present era of time-based competition. The objective and side conditions are considered for both profitability and effectiveness. Indeed, for given service response time, optimal tour plan would minimize the quantity of service personnel. This decreases the hiring cost of service personnel and thus increases the profitability of after-sale service process. On the other hand, for given quantity of service personnel, optimal tour plan would reduce the service response time. Responsive after-sale service on FCFS priority basis will increase the customer satisfaction, which in turn leads to more repeat orders and hence improves the profitability. The proposed model can capture all realistic constraints of service management process, such as time windows, skill requirement, balanced workload distribution, etc. A numerical illustration is included to demonstrate the effectiveness of the proposed model in conducting economic analysis of an after-sale service process.
\end{abstract}

Keywords: Integer programming; After-sale service process; Service personnel allocation; FCFS; Responsiveness

\section{Introduction}

After-sale service means those activities and interactions with the customers which follow a product's sale. In today's time-based competitive era, after-sale service is considered as an important means for organizations to increase profitability and to differentiate themselves from their competitors. In fact, after-sales service is perceived as a main strategic driver for business generation, brand fostering and customer satisfaction [1,2]. According to Dennis and Kambil [3], post-sale support services can also be the source of significant revenue generation. It can account for as much as $25 \%$ of revenues and $40 \%-$ $50 \%$ of profits for organizations. According to Murthy et al. [4], the profit margin for post-sale service is roughly $30 \%$ as opposed to $10 \%$ on the initial sale. However, these profit margins shrink as the competition in post-sale support gets more intensive.

The primary constituents of after-sale service process are - on time product delivery, proper installation, product usage training, product warranties, providing on-site efficient repair service for breakdowns, product upgrades and product disposal [5-7]. According to Blumberg [8], the demand for after-sale services is robust and increasing worldwide.

Responsive after-sale services are acknowledged as an important source of competitive advantage as well as a key differentiator for all organizations. Amini et al., [9] found that longer repair cycle time leads to low customer satisfaction, whereas short cycle repair strategy for products speeds the rate of adoption and increases customer loyalty. Therefore, high quality after-sale services provided in minimum service length time are helpful in maintaining long-term customer relationship. Sound relationship with customer leads to increase in customer loyalty, customer retention and firm's profitability [1012]. To make customers satisfied and delighted as well as to increase profitability, the post-sale support services need to be performed efficiently and effectively. Delivery of responsive after-sale service in a cost efficient manner becomes critical for business survival. There exist a tradeoff between service response time and quantity of service personnel (i.e., cost of providing after-sale service). Service response time can be improved by hiring more number of service personnel, but this would increase the cost. If a few number of service personnel are fired to cut cost then responsiveness decreases. Firms that can effectively allocate their available service personnel to meet after-sale service needs will significantly enhance their competitive position. To achieve rapid service response time goal with minimum quantity of service personnel, a firm needs to schedule tour of service personnel in optimal manner.

\section{Problem Statement}

With above background, the problem of allocating service personnel in after-sales service process can be stated as follows:

A company sells their products to the customer through dealers and these dealers are scattered over several cities, within cities several areas, etc. Each area or city has a set of customers $C=\left\{C_{1}, C_{2}, \ldots, C_{N}\right\}$ and each customer has different after-sale service requirement with the dealer.

The post-sale support services required by customers and

*Corresponding author: Devendra Choudhary, Department of Mechanical Engineering, Government Engineering College Ajmer, Rajasthan, India, Tel: 094629 64712; E-mail: dceca@rediffmail.com

Received December 12, 2014; Accepted March 20, 2015; Published April 10, 2015

Citation: Choudhary D, Bhamu JP, Jakhar OP (2015) An Optimization Model for Scheduling Tour of Service Personnel in after-Sale Service Process with Additional Side Conditions of Responsiveness and FCFS Service Policy. Ind Eng Manage 4 155. doi:10.4172/2169-0316.1000155

Copyright: (c) 2015 Choudhary D, et al. This is an open-access article distributed under the terms of the Creative Commons Attribution License, which permits unrestricted use, distribution, and reproduction in any medium, provided the original author and source are credited. 
communicated to dealer in current planning period are resolved in following period by $R$ service personnel situated at dealer's location. At time of noting the service request of customer, the dealer promises to resolve his/her problem within minimum service response time (SRT). At the beginning of all planning period, all $R$ service personnel, who all start and end at the dealer's location, travels each customer's location exactly once with additional side condition that all customers of his/her tour should be served by first come first serve (FCFS) based policy. They travel for time (distance) $t_{i j}$, to reach from customer $j$ to customer $j$ ' and spends some time $d_{j}$ (dwell time) at customer location $C_{j}$ to resolve his/ her post-sale problem and return back to dealer location ensuring that total cycle time (travel time + dwell time) for all service personnel is almost same and should be no more than SRT.

Based upon this information of planning period, a dealer has to decide a tour schedule with the minimum number of service personnel such that the total travel time of visiting all customers is minimized with additional side conditions of first come first serve (FCFS) based policy and specified service response time (SRT).

Thus, the dealer is concerned with the determination of appropriate manpower requirements, manpower allocation and tour scheduling in after-sale service process in order to meet its internal and external commitments. Obviously, this is an extension of personnel scheduling problem that has been extensively studied in literature $[13,14]$. Scheduling problems of personnel or staff contribute to improvement of the overall performance of a system in terms of quality of service to the customer and cost to the company.

In this paper, we propose a binary integer linear programming model for allocating service personnel in the after-sale service process problem by imposing service response time and FCFS service policy as side conditions. These realistic side conditions can find applications in many areas, such as multiple traveling salesman problem [15], vehicle routing problems $[16,17]$, and staff/crew scheduling problems [1823]. The single depot multiple traveling salesman problem (mTSP), in which $m$ salesmen starting from the single depot node have to visit exactly once each intermediate node in a given list and in the end have to return to depot node in such a way that the total time (distance) traveled is minimum, is closely related to topic of this paper. The problem taken up in this paper can be considered an extension of the $m$ TSP problem incorporating new realistic additional side conditions of service response time and FCFS service policy. These side conditions are important strategies in present era of time-based competition. In previous century, low cost and high quality was the most fundamental sources of competitive advantage. However, in current scenario, low cost and high quality is no longer sufficient for the firms to compete in the world market and firms have shifted their strategies from cost and quality to speed.

The paper is further organized as follows. Section 3 presents a binary integer linear programming model for allocation of service personnel in after-sale service process. Section 4 presents solution approach for proposed model and finds a lower and an upper bound for minimum number of service personnel needed to serve all customers when service response time is specified. Computational analysis of allocating service personnel in after-sale service processis given in section 5. Finally, conclusions are provided in section 6 .

\section{Model Formulation}

We propose following indices, parameters and decision variables for binary integer linear programming model for allocation of service personnel in the after-sale service process.

Indices

$i \quad$ set of service personnel $i=1,2, \ldots, R$

$j \quad$ set of customers $j=1,2, \ldots, N$

Parameters

SRT service response time

$t_{j j^{\prime}} \quad$ travel time between customer $j$ and customer $j^{\prime}$

$d_{j} \quad$ dwell time at customer $j$

Binary decision variables

$y_{i j} \quad 1$, if service personnel $i$ serves to customer $j$; 0 , otherwise

$z_{i j j^{\prime}} \quad 1$, if service personnel $i$ travels from customer $j$ to customer $j$; 0, otherwise

With above parameters and decision variables, an optimization is stated below:

Minimize $\sum_{i=1}^{R} \sum_{j=1}^{N} \sum_{j^{\prime}=1}^{N} t_{j j^{\prime}} z_{i j j^{\prime}}$

Subject to

$\sum_{i=1}^{R} y_{i 1}=R$

$\sum_{i=1}^{R} y_{i j}=1 j=2, \ldots, N$

$\sum_{j=1}^{N} d_{j} y_{i j}+\sum_{j=1}^{N} \sum_{j^{\prime}=1}^{N} t_{j j^{\prime}} z_{i j j^{\prime}} \leq S R T i=1, \ldots, R$

$\sum_{j=1}^{N} z_{i j j^{\prime}}=y_{i j^{\prime}} i=1, \ldots, R, j^{\prime}=1, \ldots, N$

$\sum_{j^{\prime}=1}^{N} z_{i j j^{\prime}}=y_{i j} i=1, \ldots, R, j=1, \ldots, N$

$\left(\sum_{\mathrm{k}=1}^{\mathrm{N}} \mathrm{y}_{\mathrm{ik}}-\sum_{\mathrm{k}=1}^{\mathrm{j}} \mathrm{y}_{\mathrm{ik}}\right)+\mathrm{Nz}_{\mathrm{ijj}} \leq \mathrm{Ni}=1, \ldots, \mathrm{R}, \mathrm{j}=1, \ldots, \mathrm{N}, \mathrm{j}^{\prime}=1, \ldots, j$

$y_{i j} \in\{0,1\} i=1, \ldots, R, j=1, \ldots, N$

$z_{i j j^{\prime}} \in\{0,1\} i=1, \ldots, R, j=1, \ldots, N, j^{\prime}=1, \ldots, N j \neq j^{\prime}$

The objective function (1) minimizes the overall travel time (distance) of visiting all customers. Constraint (2) ensures that exactly $R$ service personnel leave from and return to the dealer depot node. Constraints (3) ensure that each customer is visited exactly once. Constraints (4) ensure that total cycle time does not exceed to desired service response time for any service personnel. We consider some dwell time for service personnel at the dealer's location at the start of tour which is required to get allocation details, collecting tools and spare parts. Constraints (5) and (6), calculate $z_{i j i}$ from $y_{i j}$ values, and ensure that exactly a single service person travels to and leaves from the customer location. Constraints (7) prohibit the formation of any subtour between customer nodes and assign service personnel such that all customers of his/her tour should be served by first come first 
serve (FCFS) based service policy. Finally, constrains (8) and (9) force the binary restrictions on the decision variables.

In order to match the skill of service personnel with customer requirement, we set $y_{i j}=1$ in above formulation. Using this additional constraint, we can consider difference among abilities of service personnel to resolve customer's post-sale problems. Further, lower and upper bound restriction on the number of customers visited by each service person can be imposed by using below inequalities:

$$
L \leq \sum_{j} y_{i j} \leq U i=1, \ldots, R
$$

The proposed formulation can also be extended to serve each customer within a specified time window. Let customer $j$ has a time window $I=\left[a, b_{j}\right]$ within which s(he) has to be served, where $a_{j}$, is the time at which service can start and $b$ is the deadline. If a service person arrives too early at a customer location, $\mathrm{s}(\mathrm{he})$ is allowed to wait. Let $t$ denote the arrival time at customer $j$ and let $T$ be a very large number. Time window restriction for each customer can be imposed by using following constraints:

$$
\begin{aligned}
& t_{j^{\prime}}\left\{\begin{array}{l}
\geq t_{j}+d_{j} y_{i j}+t_{i j^{\prime}}-\left(1-z_{i j j^{\prime}}\right) T \\
\leq t_{j}+d_{j} y_{i j}+t_{j j^{\prime}}+\left(1-z_{i j j^{\prime}}\right) T
\end{array} i=1, \ldots, R, j=1, \ldots, N, j^{\prime}=1, \ldots, N j \neq j^{\prime}\right. \\
& a_{j} \leq t_{j} \leq b_{j} j=2, \ldots, N, b_{j} \geq d_{1}+t_{1 j}
\end{aligned}
$$

Note that if no service person travels from customer $j$ to customer $j^{\prime}, z_{i j j^{\prime}}$ is equal to 0 for all iand constraints (12) are ineffective then; otherwise $z_{i j j}$, is equal to 1 for some $i$ and then $t_{j}=t_{j}+d_{j}+t_{i j}$

When customers are to be served within specified time windows, one should not put restriction of FCFS service policy. In such a case, constraints (7) of above formulations are to be replaced by below constraints (13) to create just one route for all elements of the route set $\left\{i ; y_{i j}=1\right)$ in the same way as the formulation of traveling salesman problems.

$$
\sum_{j, j^{\prime} \in S} z_{i j j^{\prime}} \leq|S|-1 \quad \text { forall } \subseteq \subset\left\{i ; y_{i j}=1\right\} ;|S| \geq 2 ; i=1, \ldots, R
$$

The above discussion shows that the proposed formulation captures all the realistic situations for allocation of service personnel in the aftersale service process.

\section{Solution Approach}

This section deals with finding a lower and an upper bound for minimum number of service personnel needed to serve all nodes of the customers. The total cycle time $C$ of service personnel in planning period is $\sum_{j}\left(d_{j}+t_{i j}\right)$, and if this exceeds the service response time it is necessary to allocate a second service person. To determine the lower bound on quantity of service personnel, we use the approach of Nakade and Ohno (1999). Given $m$ service personnel, lower bound on total cycle time $L B[C]$ can be found from following:

$$
L B[C]=\frac{\sum_{j=1}^{N} d_{j}+(N-m+1) t_{\text {min }}}{m}
$$

The numerator equals total service time required, which consists of all dwell time plus all travel time. If we have $m$ service personnel, travel time is minimized if $m-1$ service personnel remain stationary and the remaining service person then covers $N-(m-1)=N-m+1$ nodes. Given that the minimum travel time between any two nodes is $t_{\text {min }}$, total travel time is then at least $(N-m+1)^{*} t_{\text {min }}$. We can then find $L B[m]$ from

$$
L B[m]=\{\min \min m / L B[C] \geq S R T\}
$$

which results in

$$
L B[m]=\frac{\sum_{j=1}^{N} d_{j}+(N+1) t_{\min }}{S R T+t_{\min }}
$$

The upper bound on quantity of service personnel is limited by the numbers of customers in planning period.

$$
U B[m]=N-1
$$

Finding a lower bound and an upper bound for minimum number of service personnel to serve all customers with time windows could be the subject of future research. In this paper, our solution approach then involves starting with $m$ set at its lower bound, then incrementing by 1 as necessary until the problem becomes feasible. Only a few iterations at most would be required to get feasible solution, as each additional service person provides a substantial capacity increase.

\section{Numerical Illustration}

In this section, we present a numerical illustration to show the effectiveness of proposed models for service personnel allocation and in conducting economic analysis of an after-sale service process.

Table 1 show the deterministic dwell times and travel times in minutes for a planning period of a dealer located at Ajmer, India. The dealer sells and provides onsite post-sale support services for home appliances (including televisions, air-conditioners, refrigerators, washing machines, microwave ovens) manufactured by a multinational company. Node 1 represents dealer's depot node. According to company's service policy, customers post-sale requests received in forenoon are resolved in afternoon on same day and all post-sale requests received in afternoon are resolved in the forenoon on following day, i.e., total tour cycle length for each service personnel can be at most 240 minutes.

We apply solution approach as described in section 4 to get feasible solution for this problem. The computation result, without considering time windows, obtained by LINGO is reported in Table 2. The dealer needs two service personnel to resolve post-sale requests of all the customers for current planning period within specified service response time. Note that each service person serves customers based on FCFS service rule during his/her tour.

\begin{tabular}{|c|c|c|c|c|c|c|c|c|c|c|l|}
\hline Nodes & 1 & 2 & 3 & 4 & 5 & 6 & 7 & 8 & 9 & 10 & $\mathrm{I}_{j}=\left[a_{j}, b_{j}\right]$ \\
\hline 1 & - & 23 & 5 & 22 & 5 & 9 & 25 & 21 & 8 & 20 & {$[0, S R T]$} \\
\hline 2 & 23 & - & 5 & 12 & 19 & 5 & 12 & 9 & 20 & 24 & {$[0,60]$} \\
\hline 3 & 5 & 5 & - & 24 & 25 & 9 & 6 & 14 & 15 & 8 & {$[30,180]$} \\
\hline 4 & 22 & 12 & 24 & - & 15 & 5 & 23 & 22 & 20 & 25 & {$[100,150]$} \\
\hline 5 & 5 & 19 & 25 & 15 & - & 21 & 6 & 23 & 16 & 5 & {$[0,30]$} \\
\hline 6 & 9 & 5 & 9 & 5 & 21 & - & 22 & 23 & 15 & 14 & {$[60,120]$} \\
\hline 7 & 25 & 12 & 6 & 23 & 6 & 22 & - & 22 & 14 & 19 & {$[100,140]$} \\
\hline 8 & 21 & 9 & 14 & 22 & 23 & 23 & 22 & - & 21 & 18 & {$[120,180]$} \\
\hline 9 & 8 & 20 & 15 & 20 & 16 & 15 & 14 & 21 & - & 14 & {$[30,90]$} \\
\hline 10 & 20 & 24 & 8 & 25 & 5 & 14 & 19 & 18 & 14 & - & {$[150,200]$} \\
\hline$d_{j}$ & 20 & 48 & 10 & 35 & 19 & 40 & 17 & 20 & 38 & 12 & \\
\hline
\end{tabular}

Table 1: Data set for illustration 1.

\begin{tabular}{|c|c|c|c|}
\hline \multicolumn{2}{|c|}{ Travel route } & \multicolumn{2}{c|}{ Tour cycle length } \\
\hline Serviceman 1 & Serviceman 2 & Serviceman 1 & Serviceman 2 \\
\hline$(1 \rightarrow 5 \rightarrow 7 \rightarrow 8 \rightarrow 9 \rightarrow 10 \rightarrow 1)$ & $(1 \rightarrow 2 \rightarrow 3 \rightarrow 4 \rightarrow 6 \rightarrow 1)$ & 214 & 219 \\
\hline
\end{tabular}

Table 2: Optimal tour schedule of service personnel with FCFS service policy but without time windows consideration. 


\begin{tabular}{|c|c|c|c|}
\hline \multicolumn{2}{|c|}{ Travel route } & \multicolumn{2}{c|}{ Tour cycle length } \\
\hline Serviceman 1 & Serviceman 2 & Serviceman 1 & Serviceman 2 \\
\hline$(1 \rightarrow 5 \rightarrow 9 \rightarrow 7 \rightarrow 8 \rightarrow 10 \rightarrow 1)$ & $(1 \rightarrow 3 \rightarrow 2 \rightarrow 6 \rightarrow 4 \rightarrow 1)$ & 219 & 153 \\
\hline
\end{tabular}

Table 3: Optimal tour schedule of service personnel with time windows consideration but without FCFS service policy.

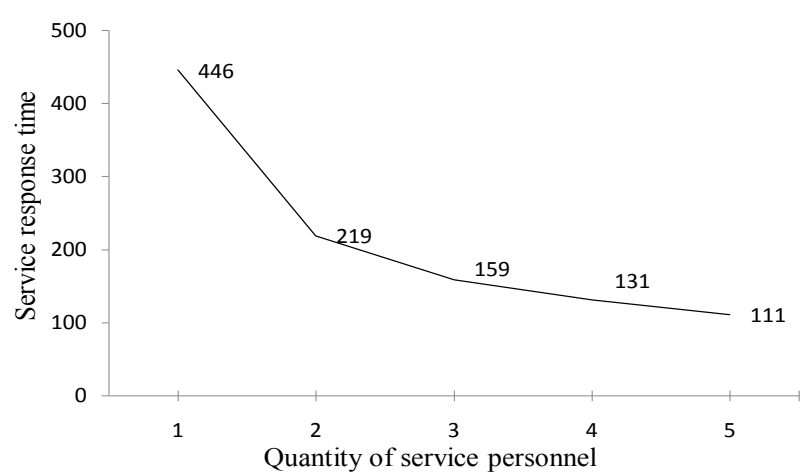

Figure 1: Tradeoff curve between service response time and quantity of service personnel.

Optimal routes for service personnel with time windows and without considering FCFS service policy are summarized in Table 3. Any change in customer specified service time window may lead to increase in quantity of service personnel.

Now, for given problem data set, a tradeoff between quantity of service personnel and service response time is analyzed. Service response time decreases as quantity of service personnel increases, and vice-versa. As shown in Figure 1, one service person is required to serve all customers when desired service response time is more than 445 minutes. Two service personnel would be needed to serve all customers when service response time is specified between 219 minutes and 444 minutes. Further, the dealer can serve all customers between 111 minutes and 130 minutes by hiring five service personnel.

In order to conduct an economic analysis of an after-sale service process, one must obtain reasonable estimates of the customers' waiting time cost for service and the cost of providing the service. Of these two costs, the customers' waiting time cost for service is usually the more difficult to evaluate. If service provider ignores the waiting time cost for service and allows long service response time, then customers feel dissatisfied. Thus, low satisfied customers will not place repeat orders in future for after-sale service and, in effect, this would decrease service provider's profitability.

The service providing cost is generally easier to determine. This cost would include the service personnel's wages, and any other direct cost associated with hiring the service person. To demonstrate the economic analysis of after-sale service process for given problem setting, the customers' waiting time cost for service and the cost of providing the service are estimated to be $\$ 1.60$ and $\$ 175$, respectively.

Figure 2 shows the general shapes of the cost curves in the economic analysis of after-sale service process. As the quantity of service personnel increases, the customers' waiting time cost for service decreases, resulting into higher customer satisfaction. But, as the quantity of service personnel increases, the cost of providing aftersale services also increases due to higher wages are to be paid to the service personnel. For given illustration, two service personnel provide the most economic after-sale services.

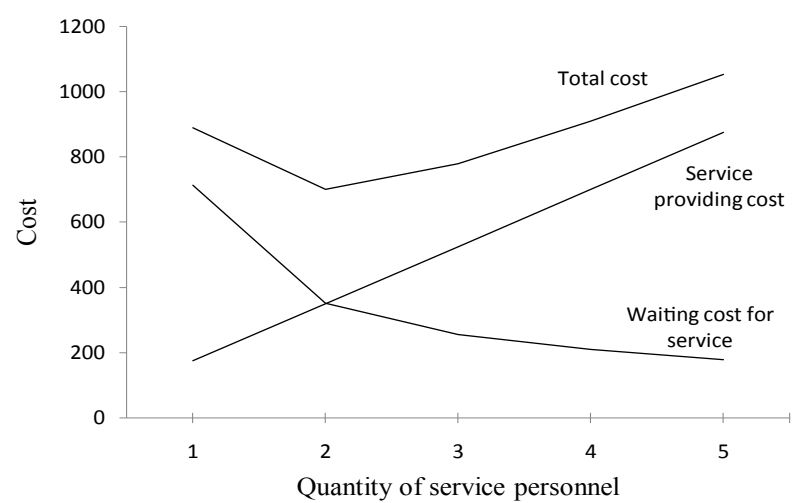

Figure 2: Cost curves for after-sale service process.

\section{Conclusions}

This paper proposes a binary integer linear programming model for scheduling the tour of service personnel with realistic side conditions of service response time and FCFS service policy. A new subtour elimination constraint is proposed for additional side condition of FCFS service policy. By incrementally varying the number of service personnel from lower bound, the proposed model can be used to optimally solve the problem of finding the minimum quantity of service personnel that can feasibly service the specified customers/ nodes in specified service response time in the most economic way. The computation analysis shows that problem of medium size can be solved using any commercial software via the proposed formulation.

As the number of service personnel or customers increases the model could become very large with thousands of binary variables and may become computationally intractable. Hence the future research work is to explore exact solution approaches such as branch and bound or cutting plane methods, or heuristics and approximate algorithms.

\section{References}

1. Anderson EW, Fornell C, Lehmann DR (1994) Customer satisfaction, market share and profitability: Findings from Sweden . Journal of Marketing 58: 58-66.

2. Cavalieri S, Gaiardelli P (2007) Aligning strategic profiles with operationa metrics in after-sales service.International Journal of Productivity and Performance Management 56:436-455.

3. Dennis MJ, Kambil A (2003) Service management: Building profits after the sale. Supply Chain Management Review.

4. Ernst A, Jiang H, Krishnamurthy M, Owens B, Sier D (2004b) Annotated bibliography of personnel scheduling and rostering. Annals of Operations Research 127:121-144.

5. Irini DR, loannis EC, Constantine L, George IS (2008) After-sales service quality as an antecedent of customer satisfaction: The case of electronic appliances. Managing Service Quality 18:512 - 527.

6. Kara I, Bektas T (2006) Integer linear programming formulations of multiple salesman problems and its variations. European Journal of Operational Research 174:1449-1458.

7. Amini MM, Retzlaff-Roberts D, Bienstock CC (2005) Designing a reverse logistics operation for short cycle time repair services. International Journal of Production Economics $96: 367-380$.

8. Heskett JL, Jones TO, Loveman GW, Sasser Jr EW (1994) Putting the service-profit chain to work. Harvard Business Review 72:164-174.

9. Persson F, Saccani N (2009) Managing the after-sales logistic network - a simulation study. Production Planning \& Control 20: 125-134. 
Citation: Choudhary D, Bhamu JP, Jakhar OP (2015) An Optimization Model for Scheduling Tour of Service Personnel in after-Sale Service Process with Additional Side Conditions of Responsiveness and FCFS Service Policy. Ind Eng Manage 4: 155. doi:10.4172/2169-0316.1000155

Page 5 of 5

10. Saccani N, Songini L, Gaiardelli P (2006) The role and performance measurement of after-sales in the durable consumer goods industries: An empirical study. International Journal of Productivity and Performance Management 55:259-283.

11. Ernst AT, Jiang H, Krishnamurthy M, Sier D (2004a) Sta $\square$ scheduling and rostering: A review of applications, methods and models. European Journal of Operational Research 153: 3-27.

12. Alfares HK (2004) Survey, categorization, and comparison of recent tour scheduling literature. Annals of Operations Research 127:145-175.

13. Fisher ML, Jaikumar $R$ (1981) A generalized assignment heuristic for vehicle routing. Networks11:109-124.

14. Laporte G (1992) The vehicle routing problem: An overview of exact and approximate algorithms . European Journal of Operational Research 59: 345358

15. Mathirajan M, Ramanathan R (2007) A (0-1) goal programming model for scheduling the tour of a marketing executive. European Journal of Operational Research 179: 554-566.

16. Murthy DNP, Solem O, Roren T (2004) Product warranty logistics: Issues and challenges. European Journal of Operational Research 156:110-126.
17. Nakade K, Ohno K (1999) An optimal worker allocation problem for a U-shaped production line. International Journal of Production Economics 61:353-358.

18. Kwan RS (2004) Bus and Train Driver Scheduling. Handbook of Scheduling CRC Press Chapter 52.

19. Kara I, Bektas T (2006) Integer linear programming formulations of multiple salesman problems and its variations. European Journal of Operational Research 174:1449-1458.

20. Emden-Weinert T, Proksch M (1999) Best practice simulated annealing for the airline crew scheduling problem. Journal of Heuristics 5:419-436.

21. Dodin B, Elimam AA, Rolland E (1998) Tabu search in audit scheduling European Journal of Operational Research 106:373-392.

22. Dennis MJ, Kambil A (2003) Service management: Building profits after the sale. Supply Chain Management Review.

23. Bektas $T$ (2006) The multiple traveling salesman problem: an overview of formulations and solution procedures. Omega 34 : 209-219. 